\title{
Analysis of surgical treatment of complex adult congenital heart disease: five years' outcomes from a single center
}

\author{
Zhang $\mathrm{R}^{1}$, Zhang $\mathrm{Y}^{1 *}$, Li $\mathrm{S}^{2}$, Yang $\mathrm{K}^{2}$, Hang $\mathrm{H}^{1}$, Meng $\mathrm{Y}^{1}$ and Chang $\mathrm{S}^{1}$ \\ ${ }^{1}$ Departments of Intensive Care Unit, Chinese Academy of Medical Sciences and Peking Union Medical College, Beijing, China \\ ${ }^{2}$ Department of Cardiovascular Surgery, State Key Laboratory of Cardiovascular Disease, Fuwai Hospital, China
}

\begin{abstract}
Aim: we analyzed the results of the surgical treatment in 149 cases of adult congenital heart disease cases (ACHD) with complex malformation.

Methods: during 2011 July to 2016 July in Fuwai Hospital, a total of 149 cases of operation treatment in ACHD of complex malformation were chosen to collect the clinical data, the type of ACHD, operation method and preoperative results were summarized and analyzed.

Results: we completed 119 correction operation cases, 30 palliative operation cases. Tetralogy of Fallot (TOF), partial anomalous pulmonary venous connection (PAPVC), transitional endocardial cushion defect (TECD), total anomalous pulmonary venous connection (TAPVC) and Ebstein anomaly were the 5 most common diseases encountered. After operation, 2 cases died, the mortality rate was $1.34 \%$. 52 cases had postoperative complications, the incidence was $34.80 \%$. The average mechanical ventilation time was $25.25 \pm 10.72 \mathrm{~h}$, the average ICU treatment time was $3.18 \pm 1.92 \mathrm{~d}$.
\end{abstract}

Conclusion: ACHD has a long personal disease history which results in obviously pathological and physiological changes, if ACHD got proper operation treatment, they cloud obtain satisfied results.

\section{Introduction}

Given medical treatment improvements have changed outcomes in congenital heart disease (CHD), more than 90\% of children born with CHD will survive to adulthood, and almost 1 in 150 young adults will have some form of adult congenital heart disease (ACHD) [1-3]. The spectrum of ACHD range from simple disorders such as atrial septal defects (ASD) to complex disorders such as transposition of great arteries (TGA), and increasingly complex ACHD patients will reach adulthood that usually require surgical correction urgently [1-3]. Adult survivors with complex congenital heart disease are expanding, evolving, and aging. Their risk of death far exceeds that in simple ACHD and in acquired heart disease [4]. This study presents 149 patients with complex ACHD from 2011 July to 2016 July in Fuwai Hospital, all of these patients' exhibit great diversity and complexity in anatomic anomalies.

\section{Materials and methods}

\section{Data collection}

According to the Bethesda classification, the patients should be classified to simple, complex, and unclassified ACHD, it must be noted that patients with coexisting complex lesions or pulmonary hypertension were classified as complex ACHD, according to the recommendations of the Bethesda classification [5]. All patients were diagnosed by Doppler-echocardiography before operation, and some patients were diagnosed by angiography. Among 788 adults $(>18$ years) with ACHD from 2011 July to 2016 July, 149 had complex adult congenital heart disease included in the study.

\section{Complex malformation disease information}

5 had tricuspid atresia (TA).

4 had single ventricle (SV).

7 had double outlet of right ventricle (DORV), 1 had DORV + TA + ASD+ ventricular septal defect (VSD)+ pulmonary stenosis (PS).

2 had pulmonary atresia (PAA)+VSD, 1 had PAA+ SV+ patent ductus arteriosus (PDA).

2 had TGA+ PAA+VSD, 2 had TGA+DORV+VSD, 1 had $\mathrm{TGA}+\mathrm{SV}+\mathrm{TA}+\mathrm{ASD}+\mathrm{PS}$.

3 had corrected transposition of great arteries (c-TGA) +VSD+PS.

34 had tetralogy of fallot (TOF), 23 had partial anomalous pulmonary venous connection (PAPVC), 14 had total anomalous pulmonary venous connection (TAPVC), 13 had Ebstein anomaly, 6 had PS.

31 had pulmonary hypertension (PH): 16 had transitional endocardial cushion defect (TECD) $+\mathrm{PH}, 2$ had TECD+ PS+

Correspondence to: Yanbo Zhang, Departments of Intensive Care Unit, Chinese Academy of Medical Sciences and Peking Union Medical College, Beijing, China, Tel: +86-101-88396614; E-mail: yanbozhang@126.com

Key words: adult congenital heart disease, complicated deformity, surgical operation treatment

Received: February 07, 2018; Accepted: February 24, 2018; Published: February 28,2018 
single atrium $(\mathrm{SA})+\mathrm{PH}, 8$ had partial endocardial cushion defect $(\mathrm{PECD})+\mathrm{PH}, 5$ had coarctation of the aorta $(\mathrm{CoA})+\mathrm{VSD}+\mathrm{PH}$.

\section{Prior procedures}

This group of patients included 4 patients previously operated on during childhood, and 145 patients with lesions that are untreated until adulthood.

\section{Surgical technique}

The current study working group reached consensus regarding patient-tailored treatment. To that purpose, we present appropriate treatment plan in individual disease characteristics, adjacent to relevant guidelines. All patients received surgical treatment, including 119 cases of correction surgery, 30 cases of palliative surgery.

\section{Statistics processing}

All analyses were performed using SPSS V.20. Data for categorical variables are reported as frequency and percentage (\%), and data for continuous variables are summarized using mean \pm SD.

\section{Results}

\section{Medical outcomes}

The study included a total of 788 admissions with ACHD across 2011 to 2016, of which 639 (81.09\%) involved subjects with simple lesions, 149 (18.91\%) were individuals with complex lesions. In this group of 149 cases, 48 cases were male and 101 were female. Mean age was $28.4 \pm 11.6$ years old. Mean weight was $53.4 \pm 12.7 \mathrm{~kg}$.

All survival patients were examined by Doppler color echocardiography, and the cardiac function was better than that before operation. 138 cases of patients with cardiopulmonary bypass (CPB) assisted, the average time of CPB $154.22 \pm 59.43 \mathrm{~min}$, in which the average blocking time of aortic occlusion was $99.29 \pm 58.75 \mathrm{~min}$. Postoperative ventilator assisted time range was $4 \mathrm{~h}-559 \mathrm{~h}$, mean time was $25.25 \pm 10.72 \mathrm{~h}$. ICU treatment time range of $1 \mathrm{~d}-30 \mathrm{~d}$, the average time was $3.18 \pm 1.92 \mathrm{~d}$. Up to now, the survival patient's heart function was significantly improved, no serious complications. The clinical characteristics among these patients were shown in Table 1.

\section{Survival}

After the operation, 2 patients died and the mortality rate was $1.34 \%$. Death case 1 was PAA+VSD had Sano surgery after Glenn surgery ten years ago, he had postoperative heart failure and renal failure assisted by blood filter, died 11 days after operation. Death case 2 was TECD $+\mathrm{PH}$, died by heart failure 12 days after operation.

\section{Spectrum of complex ACHD}

The numbers of admissions for complex defects are shown in Figure 1. Among the complex disorders, TOF, PAPVC, TECD, TAPVC and Ebstein anomaly were the 5 most common diseases encountered. Trends for distribution of demographic decreased steeply from 20-29 age group to more than 60 age group, as shown in Figure 2. TGA, PAA, CoA and DORV patients had younger operative age than others (Table 1 ), which indicated these patients were not resistant to the deformity, and they had to be treated with surgery early.

\section{Palliative surgery}

30 cases had palliative surgery. Figure 3 gives the ratio of palliative surgery and correction surgery. The numbers of different palliative surgery for complex defects are shown in Figure 4. Among the different palliative surgery, total Cavo pulmonary connection, Glenn and Sano were the 3 most common palliative surgery encountered. Specially, all patients belong to TGA, TA, SV, PAA and c-TGA need palliative surgery (Table 1).

\section{Complications}

Postoperative complications occurred in 52 patients, and the incidence was $34.89 \%$. Pneumonia occurred in 24 cases. Other complications included 4 cases of application of hemofiltration, 3 cases of pneumothorax, 2 cases of second time trachea intubation, and 1 cases of long time ventilator assisted tracheotomy. Provisional cardiac pacemaker was applied in 18 cases with hemodynamic changes due to serious cardiac arrhythmia. The pie chart gives a breakdown of where in these six parts the proportion is spent. Specially, there was no venous thromboembolism.

\section{Discussions}

The population of adults with congenital malformed hearts is increasing, more than $80 \%$ of children with $\mathrm{CHD}$ could survive into adulthood [6]. ACHD pathogenesis is a result of interactions between genes defects and the environment. New techniques and medications has led to a significant reduction in mortality rates for complex ACHD [7-8]. Surgery is the final measure when other therapy either cannot maintain adequate circulation for development or quality of life, or the

Table 1. Data statistics on the treatment of ACHD

\begin{tabular}{|c|c|c|c|c|c|c|c|c|c|}
\hline disease & number & $\begin{array}{c}\text { mean age at } \\
\text { surgery }\left(\square \chi^{ \pm \mathrm{s}}\right)\end{array}$ & composition (\%) & $\begin{array}{c}\text { palliative } \\
\text { operation ratio } \\
(\%)\end{array}$ & $\begin{array}{l}\text { extracorporeal } \\
\text { circulation time } \\
\quad(\square \chi \pm \mathrm{s}, \mathrm{min})\end{array}$ & $\begin{array}{l}\text { mechanical } \\
\text { ventilation time } \\
(\square \chi \pm s, h)\end{array}$ & $\begin{array}{l}\text { intensive care } \\
\text { unit time } \\
\left(\square \chi^{ \pm} \mathrm{s}, \mathrm{d}\right)\end{array}$ & $\begin{array}{l}\text { complications } \\
\text { rate }(\%)\end{array}$ & mortality $(\%)$ \\
\hline TOF & 34 & $32.5 \pm 10.5$ & 22.81 & $0(0)$ & $157.1 \pm 70.7$ & $25.1 \pm 18.6$ & $3.9 \pm 1.3$ & $13(38.25)$ & $0(0)$ \\
\hline PAPVC & 23 & $33.8 \pm 9.8$ & 15.43 & $0(0)$ & $73.3 \pm 30.5$ & $12.1 \pm 4.3$ & $2.3 \pm 3.3$ & $9(39.13)$ & $0(0)$ \\
\hline TECD & 18 & $32.3 \pm 11.7$ & 12.08 & $0(0)$ & $161.2 \pm 78.1$ & $27.3 \pm 14.6$ & $4.2 \pm 1.4$ & $5(27.78)$ & $1(5.6)$ \\
\hline TAPVC & 14 & $31.6 \pm 6.8$ & 9.39 & $0(0)$ & $175.4 \pm 82.9$ & $22.5 \pm 12.8$ & $2.7 \pm 1.2$ & $5(35.71)$ & $0(0)$ \\
\hline Ebstein anomaly & 13 & $29.2 \pm 10.6$ & 8.72 & $5(38.5)$ & $117.3 \pm 52.2$ & $19.9 \pm 14.6$ & $2.38 \pm 1.38$ & $4(30.76)$ & $0(0)$ \\
\hline PECD & 8 & 34.3 & 5.36 & $0(0)$ & 190.1 & 22.6 & 2.5 & $1(12.5)$ & $0(0)$ \\
\hline DORV & 8 & 24.2 & 5.36 & $5(62.5)$ & 132.2 & 20.6 & 3.5 & $2(25)$ & $0(0)$ \\
\hline PS & 6 & 31.0 & 4.02 & $0(0)$ & 168.0 & 18.5 & 2.2 & $1(16.67)$ & $0(0)$ \\
\hline $\mathrm{CoA}$ & 5 & 23.0 & 3.35 & $0(0)$ & 128 & 33.0 & 4.0 & $0(0)$ & $0(0)$ \\
\hline TGA & 5 & 21.5 & 3.35 & $5(100)$ & 79.5 & 194.5 & 11.3 & $3(60)$ & $0(0)$ \\
\hline $\mathrm{TA}$ & 5 & 21.5 & 3.35 & $5(100)$ & 154.6 & 24.0 & 4.5 & $3(60)$ & $0(0)$ \\
\hline SV & 4 & 20.5 & 2.68 & $4(100)$ & 79.7 & 15.2 & 3.5 & $2(50)$ & $0(0)$ \\
\hline PAA & 3 & 26.8 & 2.01 & $3(100)$ & 108.0 & 90.8 & 5.6 & $2(66.67)$ & $1(33.3)$ \\
\hline c-TGA & 3 & 35.6 & 2.01 & $3(100)$ & 89.3 & 28.6 & 4.3 & $2(66.67)$ & $0(0)$ \\
\hline
\end{tabular}


structural defect requires correction to prevent further damage to the heart or other organs. The significant increase in this population, the lack of professional's expertise and medical centers prepared to provide proper health care is a challenge [9-11]. Providing full care of patients with ACHD, requiring surgical treatment as a result of progression of the disease operated or diagnosed in adulthood, becomes a challenge for the future.

The complex malformations ACHD patients who survived to adulthood, their body and heart malformations reached a compromise of balance, such as patients with TOF and PAA of right ventricular outflow tract obstruction, but often have abundant body pulmonary

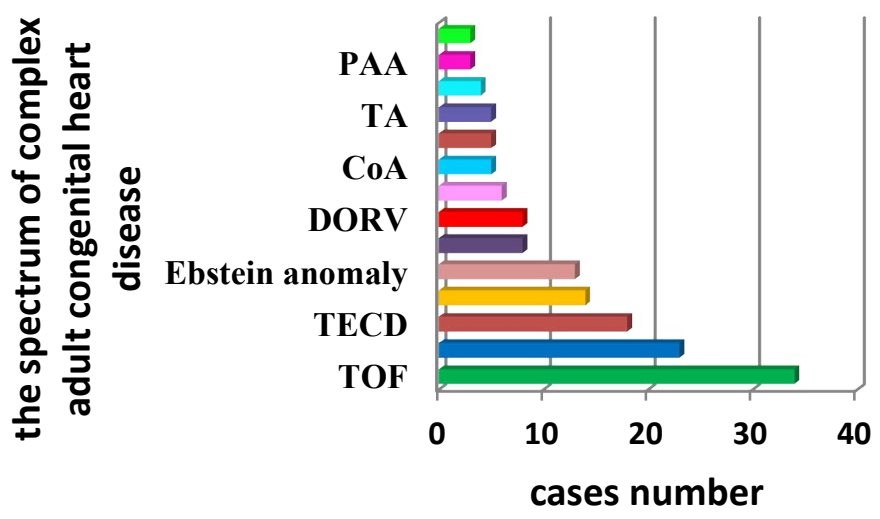

Figure 1. The figure demonstrates the spectrum of complex adult congenital heart disease The numbers of admissions for complex defects are shown as above. Among the complex disorders, TOF, PAPVC, TECD, TAPVC and Ebstein anomaly were the 5 most common diseases encountered.

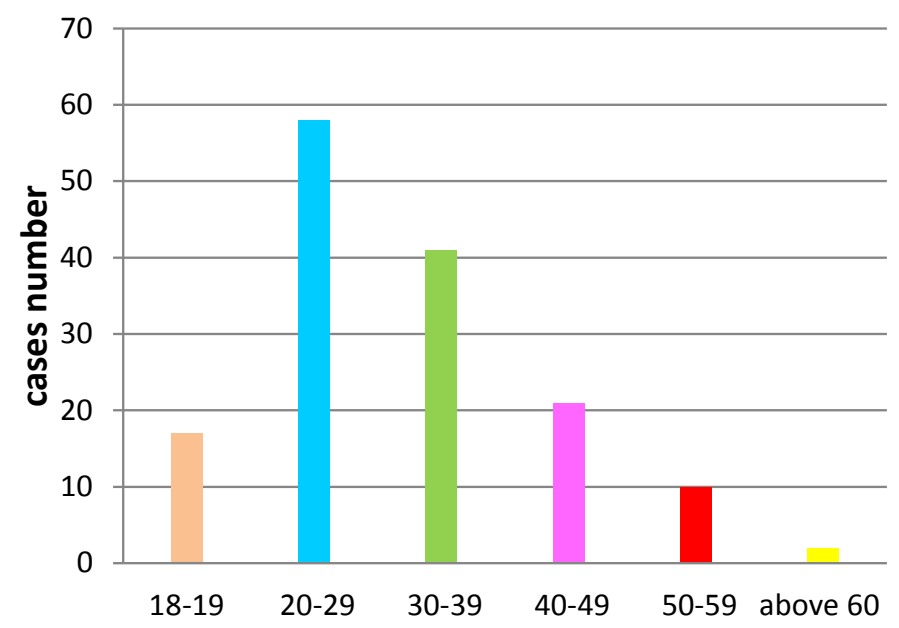

age group

Figure 2. Age distribution of adult congenital heart disease.

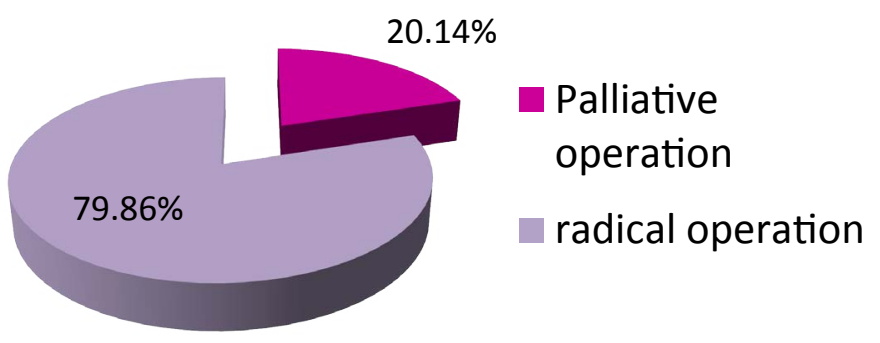

Figure 3. Ratio of palliative surgery and correction surgery.

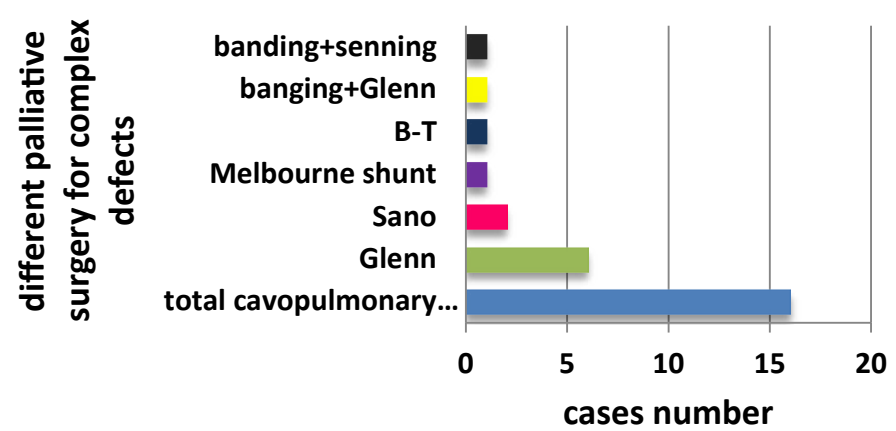

Figure 4. The numbers of different palliative surgery for complex defects are shown as above.

collateral circulation, which makes patients of pulmonary blood flow enough, but not excessive. The mean age of complex ACHD patients in the study was 28.4 years, with the oldest patient being 65 years of age. There are a large number of adult patients less than 40 years of age (117 cases, $78.52 \%$ ) who underwent surgery in the study.

The fundamental purpose of surgery is to from the perspective of long-term solution in patients with systemic and pulmonary circulation obstruction, to ease the preoperative state of hypoxia, and try to solve with valve disease. For patients with complex ACHD cannot be corrected, according to preoperative examination and ultrasound examination, our working group strict formulated individualized palliative surgery program.

The group TECD, PECD, PAPVC, TAPVC and other abnormal traffic patients had satisfactory results. CoA patients in this group were treated with left ventricular outflow tract and thoracic aorta as a whole, and the risk of spinal cord ischemia during operation was alert. Pulmonary valve annulus used to avoid malignant arrhythmia and right ventricular outflow tract tumor like dilatation of the pulmonary artery. In this group, DORV, Ebstein, TGA, TA, SV, PAA, and all the severe patients with severe c-TGA can only be used in palliative operation to introduce oxygen and blood into the body circulation.

Compared with simple congenital heart disease and adult patients with acquired heart disease, ACHD patients may have more complex problem [12]. Our routine monitoring of patients with left atrial pressure and central venous pressure, severe patients should be monitoring right atrial pressure and pulmonary artery pressure, intraoperative transesophageal echocardiography cardiac figure direct evaluation of left and right ventricular function, right and left sides of the heart valve function found residual shunt.

For postoperative pulmonary artery pressure decreased with the nitric oxide or milrinone inhalation of decrease of pulmonary vascular resistance, and the controlled ventilation carbon dioxide partial pressure is approaching $35 \mathrm{mmHg}$ following, to further control of pulmonary artery pressure.

For preoperative deformity caused by hemodynamic and hypoxia induced arrhythmia, after most of the rhythm of normal, and the surgical incision, edema, scar and no surgical deformities caused by arrhythmia, our working group used temporary pacemaker, antiarrhythmic drugs, adjustment of the internal environment, temperature control and comprehensive treatment.

Hemostasia difficulty may exist in ACHD patients. Early postoperative chest fluid, which is by ACHD long-term cardiac function, does not affect the liver function, coagulation factor reduction 
caused. In addition, ACHD longer operative time, parts before operation in patients with severe cyanosis and postoperative pleural fluid more important reason, and in some cases, palliative operation of the pipeline and combined valve replacement operation anticoagulant limited, postoperative early should actively monitor the application of thromboelastography means were positive for hemostatic measures.

In recent years, dramatic success of pediatric heart surgery treatment has changed the natural history of CHD. More complex diseases could be seen in adult patients. The most complex ACHD were referred to pediatric surgeons [13], who had lower mortality. Our hospital specializes in cardiovascular diseases, where pediatric cardiac surgery coexists with general cardiovascular surgery. The knowledge required to take care of these patients is more complex, the surgeon's knowledge included congenital heart disease, valvular operations, aorta operations, handle arrhythmia and other subspecialties, the ICU doctors should be trained in internal medicine, general cardiology, pediatric cardiology and subspecialties. Applying all this knowledge in an integrated manner can provide a better outcome in this group of patients.

Let us focus on the quality of surgical outcomes. There were two early deaths and there was no late death. Before each operation, our working group balanced gains and losses in complex measures of quality, such as the medical vs. surgical treatment of patients, operation timing and the choice of procedures. In the study, overall mortality was $1.34 \%$, PAA mortality was $33.3 \%$, and TECD mortality was $5.6 \%$. In this study, the fact that the patient of higher complexity has been treated by pediatric surgeons had an impact on the result observed when we analyzed mortality.

The complex ACHD patients in this study included who had their disease first treated in adulthood (4 cases, $2.68 \%$ ), as well as those who had their disease not operated before age 18 (145 cases, 97.32\%). This is due to that these patients got less change in accessing specialized centers and the primary healthcare service could not diagnosis. And less symptomatic patients seek medical help late in the natural evolution explain the large number of patients operated for the first time in adulthood, over 18 years. The insufficient number of centers and geographical distribution was the two-main difficult to access to the specialized centers.

\section{Conclusion}

With a growing population of adults with ACHD, improvements to our resources and infrastructure need to be considered in order to cope with the increasing demands. Establishing working groups specialized for ACHD, in line with the group of pediatric cardiology and other specialties within cardiology is urgently to ensure best results and most appropriate care for these patients. Moreover, establishing protocols for care and supporting specific needs (such as arrhythmia, for example) of this group of patients is also important. Hence, there is a need for surgeons specializing in the treatment of ACHD, as well as centers dedicate to treat them in a specialized manner.

\section{Limitation}

The limitation of our study is a longer duration of study period is required in future similar studies. This study is also limited by that all surgeries were carried out by a limited number of surgeons. This raises the issue of training more surgeons in the field of congenital cardiac surgery.

\section{References}

1. Mulder BJ (2012) Epidemiology of adult congenital heart disease: demographic variations worldwide. Neth Heart J 20: 505-508. [Crossref]

2. Baumgartner H, Bonhoeffer P, De Groot NM, de Haan F, Deanfield JE, et al. (2010) ESC Guidelines for the management of grown-up congenital heart disease (new version 2010). Eur Heart J 31: 2915-2957. [Crossref]

3. Marelli AJ, Mackie AS, Ionescu-Ittu R, Rahme E, Pilote L (2007) Congenital heart disease in the general population: changing prevalence and age distribution. Circulation 115: 163-172. [Crossref]

4. Greutmann M, Tobler D, Kovacs AH, Greutmann-Yantiri M, Haile SR, et al. (2015) Increasing mortality burden among adults with complex congenital heart disease. Congenit Heart Dis 10: 117-127. [Crossref]

5. Warnes CA, Liberthson R, Danielson GK, Dore A, Harris L, et al. (2001) Task force 1: the changing profile of congenital heart disease in adult life. J Am Coll Cardiol 37: 1170-1175. [Crossref]

6. Winlaw D (2007) Congenital heart disease in the $21^{\text {st }}$ century. Crit Care Resusc 9 270-274. [Crossref]

7. Tweddell JS, Hoffman GS (2002) Postoperative management in patients with complex congenital heart disease. Semin Thorac Cardiovasc Surg Pediatr Card Surg Annu 5: 187-205. [Crossref]

8. Hoffman TM, Wernovsky G, Atz AM, Bailey JM, Akbary A, et al. (2002) Prophylactic intravenous use of milrinone after cardiac operation in pediatrics (PRIMACORP) study. Prophylactic Intravenous Use of Milrinone After Cardiac Operation in Pediatrics. Am Heart J 143: 15-21. [Crossref]

9. Dearani JA, Connolly HM, Martinez R, Fontanet H, Webb GD (2007) Caring for adults with congenital cardiac disease: successes and challenges for 2007 and beyond. Cardiol Young 17 Suppl 2: 87-96. [Crossref]

10. Baumgartner H, Bonhoeffer P, De Groot NM, de Haan F, Deanfield JE, et al. (2010) ESC Guidelines for the management of grown-up congenital heart disease (new version 2010). Eur Heart J 31: 2915-2957. [Crossref]

11. Child JS, Freed MD, Mavroudis C, Moodie DS, Tucker AL (2008) Task force 9: training in the care of adult patients with congenital heart disease. $J$ Am Coll Cardiol 51: 389-393. [Crossref]

12. Nyboe C, Fenger-Grøn M, Nielsen-Kudsk JE, Hjortdal V (2013) Closure of secundum atrial septal defects in the adult and elderly patients. Eur J Cardiothorac Surg 43: 752757. [Crossref]

13. Caneo LF, Jatene MB, Riso AA, Tanamati C, Penha J, et al. (2012) Evaluation of surgical treatment of congenital heart isease in patients aged above 16years. Arq Bras Cardiol 98: 390-397. [Crossref]

Copyright: (C2018 Zhang R. This is an open-access article distributed under the terms of the Creative Commons Attribution License, which permits unrestricted use, distribution, and reproduction in any medium, provided the original author and source are credited. 